\title{
BMJ Open Care willingness and demand of residents under 60 years of age in western China: a cross-sectional study
}

\author{
Li nan Cheng, ${ }^{1}$ Li Zhao (1) , Xiao feng Xie, ${ }^{3}$ Liang Wang, ${ }^{4}$ Xiu ying $\mathrm{Hu},{ }^{1}$ \\ Xiao yang Dong, ${ }^{2}$ Feng ying Zhang (D) ${ }^{1}$
}

To cite: Cheng Lnan, Zhao L, Xie Xfeng, et al. Care willingness and demand of residents under 60 years of age in western China: a crosssectional study. BMJ Open 2021;11:e046515. doi:10.1136/ bmjopen-2020-046515

- Prepublication history for this paper is available online. To view these files, please visit the journal online (http://dx.doi. org/10.1136/bmjopen-2020046515).

Received 21 December 2020 Accepted 19 July 2021

Check for updates

(C) Author(s) (or their employer(s)) 2021. Re-use permitted under CC BY-NC. No commercial re-use. See rights and permissions. Published by BMJ.

${ }^{1}$ West China School of Nursing/ West China Hospital, Sichuan University, Chengdu, China

${ }^{2}$ Department of Health Policy and Management, West China School of Public Health and West China Fourth Hospital, Sichuan University, Chengdu, China

${ }^{3}$ West China Hospital/ West China School of Nursing,

Chengdu, China

${ }^{4}$ Department of Public Health, Robbins College of Health and Human Sciences, Baylor University, Waco, Texas, USA

Correspondence to

Dr Feng ying Zhang;

zhangfengying2020@163.com

\section{ABSTRACT}

Objectives The objective was to examine care willingness and demand of residents under 60 years of age after retirement.

Setting The staged cluster sampling method was used between August and October 2018 in Dujiangyan, Sichuan Province, China.

Participants 2282 participants under 60 years of age were surveyed in 2018 by the staged cluster sampling method in China.

Primary and secondary outcome measures The results of care willingness and demand were assessed by multiple comparisons of $\chi^{2}$ test and multivariable logistic regression.

Results The respondents who preferred institutionbased care, home-based care and community-based care accounted for $39.5 \%, 38.3 \%$ and $20.2 \%$ respectively, whereas only $2.1 \%$ preferred home-based self-care. The main reasons for the respondents to choose institutionbased care included better medical care (31.9\%), better daily care $(27.0 \%)$, burden reduction for children $(26.3 \%)$, better accommodation $(22.8 \%)$, satisfied living environment (21.6\%) and low consumption (12.3\%). The factors that affected care willingness and demand included age, ethnicity, educational attainment, marital status, occupation and the current type of residence.

Conclusions The results revealed the care willingness and demand of residents under 60 years of age after retirement and relevant decision factors. This study provides a certain theoretical and practical significance for the development of the care willingness mode and promotes the cognition of policy-makers and researchers, and also provides the basis for decision-making.

\section{BACKGROUND}

Population ageing is accelerating in China. It is estimated that the number of old people above 60 years, people aged above 65 years and the elderly living alone (empty nesters) will reach 255 million, 29 million and 118 million respectively by $2020 .{ }^{12}$ Ageing brings the elderly a range of care problems, such as decline in body functions, changing social roles and status, and a low sense of wellbeing. ${ }^{3}$ With the development of the national economy, improvement in people's living

\section{Strengths and limitations of this study}

This study revealed the willingness of residents under 60 years of age to access elderly care and their demand for elderly care after retirement, as well as relevant factors affecting their decision-making.

- The staged cluster sampling method ensures a representative sample in a certain region.

- Convenience sampling may limit the applicability of the results in the whole country, and the crosssectional study design does not allow for causal inference.

standards and change in family structure, the consumption needs and care demand of the elderly are also increasing, both of which lead to multilevel and diversified development.

Previous studies show that the care service system development for the elderly is still in the initial period, and that the care willingness and demand types are still in exploration. Elderly care services suffer from the imbalance between supply and demand, and some care institutions for old people fall short of the standards for care service quality ${ }^{4}$ or quality supervision. ${ }^{56}$ These factors affect not only the satisfaction of care needs for the elderly but also the stable development of society, people's health needs and the happiness index. ${ }^{78}$

In 2013, the Opinions of the State Council on Accelerating the Development of the Elderly Care Service Industry proposed the '9073 elderly care service project', the objective of which is to realise home-based care for $90 \%$ of the elderly, community-based care for $7 \%$ and institution-based care for the remaining $3 \% .^{9}$ This project is in line with Chinese traditional emphasis on family values.

The project has played a positive role in promoting the supply of elderly care services and is conducive to the reasonable allocation of resources. But studies suggest that 
the development of home-based care has encountered some obstacles in practice. On the one hand, the development of home-based care and community-based care services is not sufficient, and a sound service market has not been formed. On the other hand, it is difficult for the elderly to have high satisfaction because of the high cost of purchasing services and insufficient understanding of services. ${ }^{9}$ In addition, many old people are confused about what services to choose at present, and some cannot make decisions about elderly care service on their own due to physical and economic reasons. So, it is difficult to meet the needs of the elderly for personalised care services.

A '4-2-1 family' refers to a family with four seniors, a married couple who are both the only child of their respective family and the couple's only child. The married couple, as the middle generation, are defined as the first generation of the only child born between 1976 and 1986 . They have to support both parents (the four seniors) and one child. ${ }^{10}{ }^{11}$ As reported in 2013, the number of one child in China had exceeded 100 million, accounting for about $8 \%$ of the total population.Furthermore, the number is expected to reach about 300 million by 2050 . Demographers predict that there will be at least 10 million '4-2-1' families in China in the next 10 years. ${ }^{10-12}$ And this generation and beyond, who are highly independent and rarely live at home with their parents, face great financial pressure in care services. So changes in the values of care willingness and services after retirement, together with social and demographic trends, will largely determine the senior care service model in the coming decades. An early investigation has shown that the willingness of home-based care services decreases gradually with the decrease in age, and the willingness of young and middle-aged people in institution-based care services is significantly higher than that of old people. ${ }^{13} 14$

Dujiangyan City, a county-level city under the administration of the prefecture-level city of Chengdu in Sichuan Province, China, has an area of $1280 \mathrm{~km}^{2}$. In 2016, its population was $690900,13.92 \%$ of whom were aged 65 years or above, higher than the national average of $10.8 \%$. There were 132000 people aged 60 years and above, accounting for $20.1 \%$ of its total population. The old-age burden coefficient was $18.43 \%$, higher than the national level of $14.30 \%,{ }^{15}$ and there were 20.42 elder care beds per 1000 elderly people, which was lower than the national average of 31.6 beds. ${ }^{16}$ Given the population of elderly people, the demand for elder care services is significant. However, the supply is insufficient.

In the context of a rapidly ageing population, it is very important to effectively locate long-term care facilities. People of different age groups may have different attitudes towards elderly care needs. The existing studies on people's willingness to access elderly care and demand for elderly care after retirement mainly focus on the elderly group. There is a lack of research among other age groups. To make preparations for elderly care in advance and provide reference for the strategy to balance the supply and demand of elderly care, it is necessary to examine the willingness of residents under 60 years of age to access elderly care and their demand for elderly care after retirement. This study can contribute to a better understanding of the diversified elderly care needs and pave the way for increasing elderly care satisfaction and improving people's well-being after retirement. This cross-sectional study can help raise the awareness of policy-makers and researchers, contribute to rational allocation of care resources and provide useful information for adequate preparation and appropriate policy adjustments for the rational allocation of social care resources in advance.

\section{METHODS \\ Study design and ethical considerations}

A cross-sectional design was used in this study. The Strengthening the Reporting of Observational studies in Epidemiology (STROBE) cross-sectional reporting guidelines were used. ${ }^{17}$

\section{Data collection}

The staged cluster sampling method was used between August and October 2018 in Dujiangyan, Sichuan Province, China. Dujiangyan is composed of 10 rural townships, each of which consists of several villages, and 9 urban districts, each of which consists of several communities.

First, five townships and five districts were randomly selected. From each township or district, 200 residents were randomly selected to participate in the survey from a resident database provided by the local government. The sample was planned using a Sojump online survey (Questionnaire Star Survey Website) that enabled rapid and effective distribution of an online questionnaire to the participants. We provided sufficient explanation at the beginning of the online survey, and the participants voluntarily and anonymously participated in this study. Meanwhile, all the participants were asked to answer two questions (whether they agreed to participate in the survey and whether they agreed to submit the survey for this study) to complete the online written consent for ensuring informed consent. They were given $30 \mathrm{~min}$ to complete the questionnaires. Considering the possibility of invalid questionnaires, we increased the sample size by $20 \%$ on the basis of the target sample size. Overall, 2400 questionnaires were distributed.

\section{Quality control}

Before the survey, we selected five participants for a pilot test and modified the questionnaire. For example, we adjusted the number of items to ensure reasonable response time, optimised the contents and improved the wording. During the pilot test, two researchers especially responsible for the supervision and collection of questionnaires timely supervised the completion of questionnaires and adjusted information feedback. After the test, we strictly screened the data to ensure the accuracy. For 
Inclusion criteria:

(a) Participants who had given informed consent;

(b) Participants who were under 60 years old;

(c) Participants who had normal comprehension.

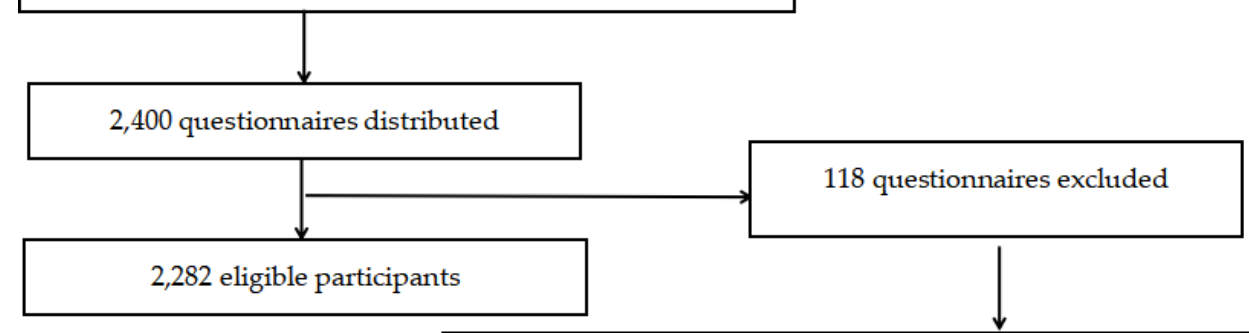

Exclusion criteria:

(a) Questionnaires not completed by the participants.

(b) Questionnaires filled out by participants who were over 60 years old.

(c) Questionnaires filled out with consistently repeated options.

(d) Questionnaires completed using less than the standard time (15 minutes).

Figure 1 The flowchart for inclusion and exclusion of participants.

instance, according to the inclusion criteria of the study, we selected one participant from 10 occupations, respectively, and filled in the questionnaire in the normal way. Finally, the mean value (15 min) was calculated as the final analysis standard according to the completion time of all participants.

\section{Participants}

The participants who met the following inclusion criteria were included: permanent residents who (a) provided the informed consent to participate, (b) were under 60 years of age and (c) had normal comprehension. A total of 2400 participants participated in the survey using the Questionnaire Star Survey Website. However, 118 (4.9\%) of 2400 questionnaires were taken out of the sample according to the exclusion criteria: (a) questionnaires not completed by the participants, (b) questionnaires filled out by participants who were above 60 years of age, (c) questionnaires filled out with consistently repeated response options, (d) questionnaires completed in less than the standard time (15 min) and (e) questionnaires filled out by participants who did not agree to participate in the survey or by those who did not agree to submit the survey for this study. Finally, a total of 2282 (a response rate of $95.1 \%$ ) eligible participants were left (figure 1).

\section{Instruments}

The survey included questions assessing the participants' demographic characteristics (gender, ethnicity, chronic disease, educational attainment, marital status, occupation, current type of residence, future care willingness and personal income), assessment of the community living environment and assessment of the healthy city index.

Assessment of the community living environment was self-designed according to the city development plan.
Specifically, the participants were asked to answer questions about the areas within 10-15 min of walk from their homes. The questionnaire contains 15 items, including the availability of public infrastructure, transportation facilities, relaxation and entertainment facilities, and community safety. Responses were provided on a fivepoint scale from 1 (strongly disagree) to 5 (strongly agree), with the total possible score ranging from 15 to 75 points. A higher score indicated greater recognition. Scores over 55 points were classified as high, those between 35 and 54 points as medium and those less than 35 as low. In this study, the Cronbach's alpha coefficient was 0.867 .

Assessment of the healthy city index was also selfdesigned. This section contains seven items, including air quality, water quality, waste disposal, number of vectors in public places in daily contact, restaurant hygiene, health sports activities and whether they knew or had heard of various health campaigns and popularisation activities. Responses were provided on a five-point scale from 1 (strongly agree) to 5 (strongly disagree). A lower score indicated greater recognition. Scores above 23 points were classified as high, those between 15 and 23 points as medium and those less than 15 as low. In this study, the Cronbach's alpha coefficient was 0.566 .

\section{Patient and public involvement}

Patients were not involved in the design and conduct of this research; however, the public were involved in the design and conduct of this research.

\section{Statistical analysis}

All data were analysed by SPSS (V.23.0; IBM, Armonk, New York, USA). Descriptive statistics were presented as mean or median, frequencies or percentages. 
To compare the results and characteristics among residents under 60 years of age, the multiple comparisons of $\chi^{2}$ test was used for comparison among different groups for care willingness. The results of logistic regression analysis were expressed as ORs with $95 \%$ CIs. The variables were entered at 0.05 and removed at 0.10 by the Enter method. A $p$ value of $<0.05$ was considered statistically significant. And in the multiple comparisons of $\chi^{2}$ test, the level of $0.05 / 6=0.008$ was considered statistically significant.

\section{RESULTS}

\section{Demographic results}

This study included a total of 2282 participants under 60 years of age. Of the participants, 1520 (66.6\%) were women and $2238(98.1 \%)$ were Han Chinese. The mean age range is 36.87 years ( $\mathrm{SD}=9.62$; range $=19-59$ years $)$. Besides, $88.4 \%$ had chronic diseases. The majority were married, and $1858(81.4 \%)$ reported a personal monthly income of less than 4000 yuan, while only 65 (2.8\%) reported a personal monthly income of more than 7000 yuan. We classified four occupations according to their nature. Specifically, 1699 $(74.5 \%)$ used to work in enterprises or public institutions (including civil servants, public procurators, teachers and medical staff), $303(13.3 \%)$ were unemployed (including junior high school graduates, senior high school graduates and college graduates), $193(8.5 \%)$ were farmers and 87 $(3.8 \%)$ were freelancers (including workers). Most respondents reported that they lived in apartments (53.5\%). Besides, 901 (39.5\%) and $874(38.3 \%)$ of the respondents reported that they would choose institution-based care (including institutions that combine institution-based care and medical care) and home-based care, respectively, whereas $460(20.2 \%)$ reported community-based care. Only $47(2.1 \%)$ reported home-based self-care. More than half of them had a college degree or above. As to assessment of the healthy city index and assessment of the community living environment, the mean scores were 16.18 $(\mathrm{SD}=3.36$; range $=7-31)$ and $52.97(\mathrm{SD}=10.56$; range $=15-$ 75) respectively. The main reasons for the participants to choose institution-based care included better medical care $(31.9 \%)$, better daily care $(27.0 \%)$, burden reduction for children $(26.3 \%)$, better accommodation $(22.8 \%)$, satisfied living environment (21.6\%) and low consumption (12.3) (see table 1).

\section{Factors associated with care willingness and demand after retirement}

In this study, the factors that affected care willingness included age, ethnicity, educational attainment, marital status, occupation and the current type of residence. Paired comparison results showed that Han Chinese participants preferred community-based care to home-based self-care, whereas ethnic minority participants preferred homebased self-care to community-based care. Participants aged under 39 years preferred home-based care, whereas participants aged 40-59 years preferred institutional-based care. Participants with college degree or above preferred community-based care to home-based care. Participants without college degree preferred home-based care. Participants who were married/divorced or separated preferred institution-based care or community-based care, whereas people who were widowed/unmarried preferred homebased care or home-based self-care. People who used to work in enterprises or public institutions, freelancers and people who lived in villadoms or apartments all preferred institution-based care to home-based care $(p<0.008)$ (see table 2).

Compared with home-based self-care, multivariate logistic regression indicated that characteristics such as Han ethnicity (vs minority ethnicity) were associated with institution-based care (OR=4.652, 95\% CI=1.262 to 17.141) and community-based care $(\mathrm{OR}=6.866,95 \% \mathrm{CI}=1.553$ to 30.355 ), whereas the experience of having worked in enterprises or public institutions (vs unemployment) was associated with institution-based care $(\mathrm{OR}=2.813,95 \% \mathrm{CI}=1.305$ to 6.061$)$ and home-based care $(\mathrm{OR}=2.760,95 \% \mathrm{CI}=1.281$ to 5.946) (see table 3).

\section{DISCUSSION}

In the face of the accelerating pace of ageing, exploring and establishing different models of care willingness and demand that meet different levels of needs have always been a key concern and focus of previous research. In our study, there are four models, namely, institution-based care, home-based care, community-based care and homebased self-care in order of the choice willingness from the highest to the lowest. The main reasons for the participants to choose institution-based care were better medical care, better daily care, burden reduction for children and better accommodation. The factors that affected care willingness included ethnicity, educational attainment, marital status, occupation and the current type of residence. In addition, we also found that compared with home-based self-care, characteristics such as Han ethnicity (vs minority ethnicity) were associated with institution-based care and communitybased care, whereas employment with enterprises or public institutions (vs unemployment) was associated with institution-based care and home-based care.

As reported, people of different ages have different care willingness after retirement. ${ }^{16}{ }^{18}$ In this study, the participants preferred institution-based care and home-based care, which were consistent with other studies . In this study, participants aged $40-59$ years preferred institutional-based care. Models of the participants' care willingness varied according to factors such as the level of economic development, age characteristics and health status. ${ }^{19}{ }^{20}$ On the one hand, the development and improvement of national care service institutions for the elderly, especially the combination of medical care and care institutions, have changed the disadvantages of traditional care service institutions and satisfied the multilevel and comprehensive needs of modern people for care service providers. ${ }^{21}$ The results of this study verified that better medical care and better daily care were the main reasons for the participants to prefer 
Table 1 Demographic and social characteristics of the sample

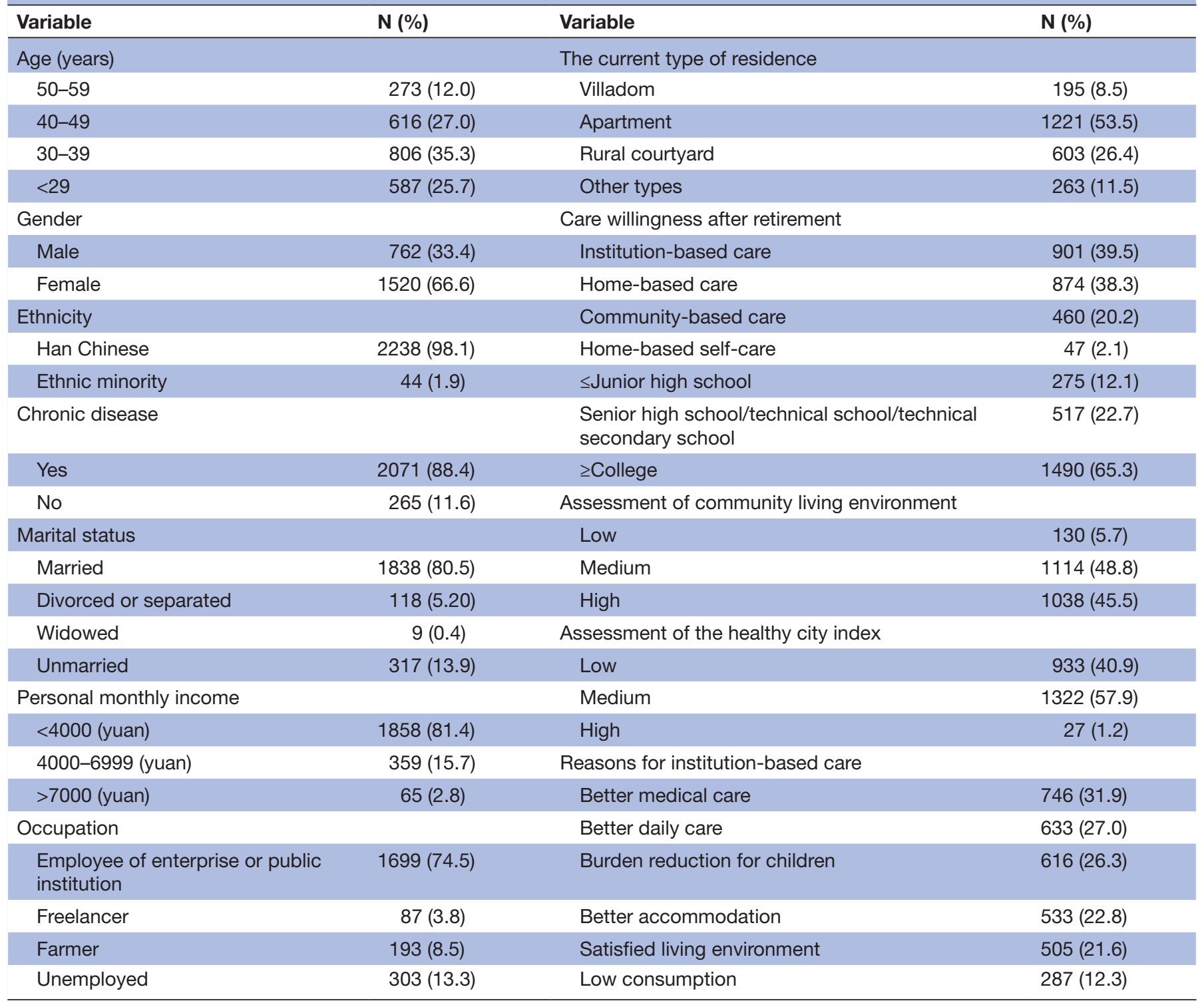

institution-based care. On the other hand, the participants under 60 years of age were in a special period of obvious changes in family structure. With the increasing number of families with fewer children and empty-nest families, ${ }^{20}$ the function of family care has been gradually weakened. As a result, more people prefer institution-based care. Despite this, the model of home-based care is still one of the main care modes. Meanwhile, the results also indicated the rise of community-based care and home-based self-care along with social development.

As we all know, China is composed of 56 ethnic groups (including 55 minority ethnic groups), with Han Chinese as the majority. And different minority ethnic groups have their unique values and ways of life, ${ }^{22}$ but priority is given to Han ethnicity. So paired comparison showed that between community-based care and home-based self-care, Han Chinese participants preferred community-based care, which can satisfy most of their lifestyles. However, ethnic minority participants preferred home-based self-care, which can meet their personalised requirements. The results also implied that personalised care model should be paid attention to and supported.

Studies have shown that educational attainment is also one of the factors affecting the choice of care willingness and demand for the elderly. ${ }^{2324}$ Participants with college degree or above prefer community-based care to home-based care. At present, most people have insufficient understanding of community-based care services. Community-based care services are mainly available in economically developed regions, cities or pilot cities of community-based care services often inhabited by people with high educational attainment. However, people with relatively low educational attainment generally live in small cities or rural areas and do not know enough about community-based care. Some even do not understand community-based care services at all. ${ }^{2}$ So strengthening publicity and raising the public awareness of community-based care services are of great significance for the improvement of relevant policies. 
Table 2 Results of the future care willingness and demand of residents under 60 years of age

\begin{tabular}{|c|c|c|c|c|c|c|c|}
\hline Variables & & $\begin{array}{l}\text { Institution- } \\
\text { based care } \\
(\mathrm{n}=901)^{\mathrm{a}}\end{array}$ & $\begin{array}{l}\text { Home-based } \\
\text { care }(n=874)^{b}\end{array}$ & $\begin{array}{l}\text { Community-based } \\
\text { Care }(n=460)^{c}\end{array}$ & $\begin{array}{l}\text { Home-based } \\
\text { self-care } \\
(n=47)^{d}\end{array}$ & $x^{2}$ & $P$ value \\
\hline \multirow[t]{4}{*}{ Age (years) } & $\leq 29$ & $194(21.5)$ & $258(29.5)$ & 121 (26.3) & $14(29.8)$ & 84.379 & 0.000 \\
\hline & $30 \sim 39$ & $263(29.2)$ & 339 (38.8) & $189(41.1)$ & 15 (31.9) & & \\
\hline & $40 \sim 49$ & 284 (31.5) & $208(23.8)$ & $108(23.5)$ & $16(34.0)$ & & \\
\hline & $\geq 50$ & $160(17.8)$ & $69(7.9)$ & $42(9.1)$ & $2(4.3)$ & & \\
\hline \multirow[t]{2}{*}{ Ethnicity } & Han Chinese & $886(98.3)$ & $853(97.6)$ & 455 (98.9) & 44 (93.6) & 8.025 & 0.045 \\
\hline & Ethnic minority & $15(1.7)$ & $21(2.4)$ & $5(1.1)$ & $3(6.4)$ & & \\
\hline \multirow[t]{3}{*}{$\begin{array}{l}\text { Educational } \\
\text { attainment }\end{array}$} & $\begin{array}{l}\leq \text { Junior high } \\
\text { school }\end{array}$ & 71 (7.9) & $152(17.4)$ & $44(9.6)$ & $8(17.0)$ & 44.294 & 0.000 \\
\hline & $\begin{array}{l}\text { Senior high } \\
\text { school/technical } \\
\text { school/technical } \\
\text { secondary school }\end{array}$ & 205 (22.8) & $200(22.9)$ & $103(22.4)$ & $9(19.1)$ & & \\
\hline & $\geq$ College & 625 (69.4) & $522(59.7)$ & $313(68.0)$ & $30(63.8)$ & & \\
\hline \multirow{4}{*}{ Marital status ${ }^{\star}$} & Married & $739(82.0)^{a}$ & $693(79.3)^{b}$ & $369(80.2)^{c}$ & $37(78.7)^{d}$ & 26.141 & 0.002 \\
\hline & $\begin{array}{l}\text { Divorced or } \\
\text { separated }\end{array}$ & $52(5.8)$ & $31(3.5)$ & 33 (7.2) & $2(4.3)$ & & \\
\hline & Widowed & $1(0.1)$ & $5(0.6)$ & $1(0.2)$ & $2(4.3)$ & & \\
\hline & Unmarried & 109 (12.1) & $145(16.6)$ & 57 (12.4) & $6(12.8)$ & & \\
\hline \multirow[t]{4}{*}{ Occupation } & $\begin{array}{l}\text { Employee of } \\
\text { enterprise or } \\
\text { public institution }\end{array}$ & 715 (79.4) & $623(71.3)$ & 332 (72.2) & $29(61.7)$ & 42.033 & 0.000 \\
\hline & Freelancer & $32(3.6)$ & $30(3.4)$ & $23(5.0)$ & $2(4.3)$ & & \\
\hline & Farmer & $48(5.3)$ & 107 (12.2) & $34(7.4)$ & $4(8.5)$ & & \\
\hline & Unemployed & $106(11.8)$ & $114(13.0)$ & $71(15.4)$ & $12(25.5)$ & & \\
\hline \multirow{4}{*}{$\begin{array}{l}\text { Current type } \\
\text { of residence }\end{array}$} & Villadom & $84(9.3)$ & 72 (8.2) & $37(8.0)$ & $2(4.3)$ & 18.853 & 0.026 \\
\hline & Apartment & $515(57.2)$ & $433(49.5)$ & $249(54.1)$ & $24(51.1)$ & & \\
\hline & Rural courtyard & 202 (22.4) & $262(30.0)$ & $126(27.4)$ & $13(27.7)$ & & \\
\hline & Other types & 202 (11.1) & 262 (12.2) & $126(10.4)$ & $13(17.0)$ & & \\
\hline
\end{tabular}

$\mathrm{p}<0.008$.

${ }^{\star}$ Refers to a vs b, a vs d, b vs $c$ and $c$ vs $d$ in pairs $(p<0.008)$.

In general, marriage is the most important support factor for a family, and people who lack family or social support tend to actively seek external help. However, in our study, people who were married/divorced or separated preferred institution-based care or community-based care, and people who were widowed/unmarried preferred home-based care or home-based self-care, which was inconsistent with relevant reports. ${ }^{25}{ }^{26}$ In our view, this phenomenon can be explained by three reasons. First, those who have a spouse prefer family or group support to reduce their loneliness, ${ }^{27}$ and they prefer institution-based care or community-based care to meet such need. And others may have become accustomed to living alone and undisturbed or have their own unique ways of life that they are reluctant to change. Second, the economic improvement and the development of various care services have given people more choices. Correspondingly, the participants of this study all rated their community living environment and the healthy city index above moderate level. Third, the results may be related to the characteristics of the sample. Specifically, the sample was under 60 years of age, not yet retired, in good health and able to take care of themselves. ${ }^{28}$

Our study also found that occupation and the current type of residence affect care willingness and demand. Previous employees of enterprises or public institutions and freelancers preferred institution-based care. By analysing the reasons, we identified burden reduction for children and low consumption as the main factors. Previous employees of enterprises or public institutions had limited stable income, and freelancers did not have stable income. So they were worried about their financial capacity to some extent. In addition, the fact that every family had only one child also reinforced their mentality that they did not want to burden their children. Although people who lived in villadoms or apartments preferred institution-based care to home-based care, their reasons vary. Specifically, people who lived in 
Table 3 The results of the multiple logistic regression analysis

\begin{tabular}{|c|c|c|c|c|c|c|c|}
\hline Variables & & B & SE & Wald & df & $P$ value & OR $(95 \% \mathrm{Cl})$ \\
\hline \multirow{3}{*}{$\begin{array}{l}\text { Institution- } \\
\text { based care }\end{array}$} & Intercept & 0.651 & 0.941 & 0.478 & 1 & 0.489 & \\
\hline & $\begin{array}{l}\text { Ethnicity (Han Chinese vs Ethnic } \\
\text { minority) }\end{array}$ & 1.537 & 0.665 & 5.337 & 1 & 0.021 & 4.652 (1.262 to 17.141$)$ \\
\hline & $\begin{array}{l}\text { Occupation (employees of } \\
\text { enterprise or public institutions vs } \\
\text { the unemployed) }\end{array}$ & 1.034 & 0.392 & 6.969 & 1 & 0.008 & $2.813(1.305$ to 6.061$)$ \\
\hline $\begin{array}{l}\text { Home-based } \\
\text { care }\end{array}$ & $\begin{array}{l}\text { Occupation (employees of } \\
\text { enterprises or public institutions vs } \\
\text { the unemployed) }\end{array}$ & 1.015 & 0.392 & 6.717 & 1 & 0.010 & 2.760 (1.281 to 5.946$)$ \\
\hline \multirow{2}{*}{$\begin{array}{l}\text { Community- } \\
\text { based care }\end{array}$} & Intercept & -0.117 & 1.019 & 0.013 & 1 & 0.909 & \\
\hline & $\begin{array}{l}\text { Ethnicity (Han Chinese vs Ethnic } \\
\text { minority) }\end{array}$ & 1.927 & 0.758 & 6.453 & 1 & 0.011 & 6.866 (1.553 to 30.355$)$ \\
\hline
\end{tabular}

Reference standard: home-based self-care.

$p<0.05$. The regression model: $\chi^{2}=100.804, p=0.000$. Pearson's $\chi^{2}=2372.570(p>0.05)$ and deviance $\chi^{2}=1970.731(p>0.05)$.

villadoms may be concerned with better medical care and better daily care that they may need in family, whereas people who lived in apartments may be more concerned with better accommodation and satisfied living environment that they need, in addition to medical care and better daily care.

Of the participants, 1520 (66.6\%) were women and 762 $(33.4 \%)$ were men, and they were randomly selected to participate in the survey. However, gender had no statistical significance in the statistical analysis of factors associated with care willingness and demand among institution-based care, home-based care, community-based care and homebased self-care. And gender was also not included in multivariate logistic regression. We think it may have two reasons. First, gender is not a main factor that affects their care willingness and demand; second, the nature of quantitative research methods limits the expression of care willingness and demand. Therefore, we may need to add qualitative research methods in the future to ensure accuracy and intelligibility.

In addition, we further found through multivariate logistic regression that occupational differences influenced the types of care. Compared with home-based self-care, participants who used to work in enterprises or public institutions (vs the unemployed) preferred institution-based care and home-based care. This may be related to the low level of awareness among the unemployed because they may have not well considered the issue of care after retirement. And it also showed that our publicity was not enough, and some people had not made adequate psychological preparations for the decisions they will face in the future. Therefore, in addition to improving the system of care, the understanding and support of different groups should also be considered in the future.

\section{Limitation}

This study has several limitations. First, the survey was conducted online to reach a large research population in a short time. As a result, we might not be able to observe whether the participants took the survey seriously. However, we took some measures to ensure the authenticity of the data, such as strict exclusion criteria to rule out the questionnaires with consistently repeated response options and those filled out using less than the standard time. Second, self-reported questionnaires may not truly reflect the thoughts of the respondents due to the intrinsic limitation of this data collection method, but this limitation may not negatively influence the results. In addition, a convenience sampling (in one city) might limit the universality of the results. Therefore, large-scale sampling would be necessary. Finally, our conclusions are based on the cross-sectional data from a one-time measurement of the variables. We also need to conduct a longitudinal survey to get the rules and changes according to the economic status of domestic residents and the development status of the senior care industry. Despite these limitations, our study does have several implications.

\section{CONCLUSIONS}

Our results revealed the care willingness and demand of residents under 60 years of age after retirement and some decision factors. The models of institution-based care and home-based care were at the top, while the models of homebased care and home-based self-care were also emerging. By analysing the influencing factors, more models of care willingness will emerge based on people's personalised care needs in the future. Therefore, large-scale dynamic survey research is needed in the future. This study has theoretical and practical implications for the development of the care willingness model, raises the awareness of policy-makers and researchers, and provides a basis for decision-making. Therefore, to develop a multilevel care willingness model that conforms to the law of social development, prospective 
study, planning and development of demand-oriented programmes are necessary.

Acknowledgements We are grateful to all the survey participants, our colleagues who participated in the study and our collaborators who have contributed to the study.

Contributors All the authors of the article contributed to the paper. LC was involved in conceptualisation and methodology. LW and XX were involved in formal analysis. LC and FZ were involved in writing - original draft preparation. XH, $F Z, L Z$ and $X D$ were involved in writing - review and editing. FZ was involved in supervision. LZ and FZ were involved in project administration. FZ was involved in funding acquisition. All authors have read and agreed to the published version of the manuscript.

Funding This study is supported by the research grant from the National Natural Science Foundation of China (grant no. 71871147).

Competing interests None declared.

Patient and public involvement Patients and/or the public were involved in the design, or conduct, or reporting, or dissemination plans of this research. Refer to the Methods section for further details.

Patient consent for publication Not required.

Ethics approval Ethical approval of this study was granted by the Biomedical Research Ethics Committee of West China Hospital, Sichuan University (ethics number: 2020-688). Participants voluntarily and anonymously participated in this study. All the data collected were kept confidential and used for this study only.

Provenance and peer review Not commissioned; externally peer reviewed.

Data availability statement Data are available upon reasonable request. The data sets used and/or analysed during the current study are available from the corresponding author on reasonable request.

Open access This is an open access article distributed in accordance with the Creative Commons Attribution Non Commercial (CC BY-NC 4.0) license, which permits others to distribute, remix, adapt, build upon this work non-commercially, and license their derivative works on different terms, provided the original work is properly cited, appropriate credit is given, any changes made indicated, and the use is non-commercial. See: http://creativecommons.org/licenses/by-nc/4.0/.

\section{ORCID iDs}

Li Zhao http://orcid.org/0000-0002-6297-528X

Feng ying Zhang http://orcid.org/0000-0003-2155-9527

\section{REFERENCES}

1 Zhang LW, Zeng YB, Wang LX, et al. [The status quo of service quality evaluation of pension institutions in China and research progress]. Zhonghua Liu Xing Bing Xue Za Zhi 2018;39:1524-9.

2 Liu R, Zhao W, Wang L. Current situation and Improvement Strategies of community home care services under the 'Silver Boom'. Chin J Gerontology 2020;40:1562-5.

3 Gildner TE, Snodgrass JJ, Evans C, et al. Associations between physical function and subjective well-being in older adults from low- and middle-income countries: results from the study on global ageing and adult health (SAGE). J Aging Phys Act 2019;27:213-21.

4 Lowe M, Coffey P. Effect of an ageing population on services for the elderly in the Northern Territory. Aust Health Rev 2019;43:71-7.

5 Fan G, Deng Z, Wu X, et al. Medical insurance and health equity in health service utilization among the middle-aged and older adults in China: a quantile regression approach. BMC Health Serv Res 2020;20:553.

$6 \mathrm{Li} \mathrm{X}$, Fan L, Leng SX. The aging tsunami and senior healthcare development in China. J Am Geriatr Soc 2018;66:1462-8.
7 Wu C, Newman AB, Dong B-R, et al. Index of healthy aging in Chinese older adults: China health and retirement longitudinal study. J Am Geriatr Soc 2018;66:1303-10.

8 Zhang Y, Yeager VA, Hou S. The impact of community-based supports and services on quality of life among the elderly in China: a longitudinal study. J Appl Gerontol 2018;37:1244-69.

9 Pan R. The Predicament and Outlet of ' 9073 ' old-age service Pattern - Based on the investigation and research of the current situation of old-age service construction in Tianjin. China Business \& Trade 2020;4:105-7.

$10 \mathrm{Hu} \mathrm{H}$, Yan H. The Construction of the Integrated Welfare Facilities for Elderly and Children Based on the '421' Family Structure in the Community. Human Settlements Forum in West China 2017;32:35-41.

11 Lu S, Yuan Y. An analysis of the future pension model of 421 Families- an empirical study based on the pension concept of the post-8090 generation. JuanZong 2016;6:402-3.

12 Feng $M$. The influence of ' 421 ' families pattern on residents' care services mode. Business 2016;3:60.

$13 \mathrm{Pu} \mathrm{H}, \mathrm{Li} \mathrm{S}$. Status and trend of the desirable caring patterns for elderly of different generation in Chengdu City. China Medical Herald 2019;16:68-71.

14 Huang M. A study on the factors association with preferences for institutional care of the elderly in Chengdu City.Master degree thesis. Chengdu: Southwest Jiaotong University, 2018.

15 Government DCPs. Statistical Communique of the National economic and social development of Dujiangyan City. Available: http://www.sc.gov.cn/10462/10464/10465/10574/2017/3/7/ 10416360.shtml [Accessed 02 Sep 2020].

16 Commission DaR. The Ministry of civil Affairs and national development and reform Commission printed the thirteenth five-year plan for the development of civil Affairs. Available: http://www.gov. cn/xinwen/2016-07/06/content_5088745.htm [Accessed 02 Sep 2020].

17 Wang Y, Xie J, Pei F. Plasma D-dimer and fdp are promising biomarkers to predict perioperative fibrinolysis and bleeding following primary total joint arthroplasty: a STROBE compliant article. Medicine 2021;100:e26058.

18 Wang Z, Sun X, Su S. The willingness to provide for the aged and its influencing factors in urban young and old people. Chin J Gerontol 2019;39:5101-4.

19 Long X, Li X, Song F. Demand and influencing factors of aged-care modes of the elderly in the Northern region of Sichuan Province. Nurs J Chin People's Liberation Army 2018;35:41-5.

20 Deng N, Lu J. A study of economic factors on the cognition and intention of integrated medical care and care institutions. Chin $\mathrm{J}$ Gerontol 2017;37:2821-3.

21 Feng Z. Childlessness and vulnerability of older people in China. Age Ageing 2018;47:275-81.

22 Hu F-W, Wang P, Li L-J. Psychometric structure of the Chinese multiethnic adolescent cultural identity questionnaire. Psychol Assess 2014;26:1356-68.

23 Wang Y, Tian F, Fan N. Elderly residents' awareness, attitude and willingness-to-pay for elderly care medical institutions: an empirical analysis based on Chengdu. Chin J Health Policy 2017;10:18-22.

24 Penkunas MJ, Eom KY, Chan AW-M. Classification trees for identifying non-use of community-based long-term care services among older adults. Health Policy 2017;121:1093-9.

25 Leng Z, Guo Q, Liu L. Preference and influencing factors for institute-based care of the elderly in Zhejiang Province. J Prev Med 2019;31:545-8.

$26 \mathrm{Wu} \mathrm{C}-\mathrm{Y}, \mathrm{Hu} \mathrm{H}-\mathrm{Y}$, Huang N, et al. Determinants of long-term care services among the elderly: a population-based study in Taiwan. PLoS One 2014;9:e89213.

27 Rezaeipandari H, Ravaei J, Bahrevar V, et al. Social participation and loneliness among older adults in Yazd, Iran. Health Soc Care Community 2020;28:2076-85.

28 Gilmour H. Unmet home care needs in Canada. Health Reports 2018;29:3-11. 